\title{
DIE BEVEILIGING VAN ROBOTIESE WERKSTASIES
}

\author{
Cornelius J. Fourie en Freda Potgieter
}

\section{OPSOMMING:}

Hierdie artikel handel oor die beveiliging van 'n robotiese werkstasie op verskillende vlakke. Dit spreek ook die koste verbonde aan beveiliging aan en gee enkele voorbeelde van veilige werkstasies. Die wetlike aspekte van beveiliging word ook gedek.

\section{ABSTRACT:}

This paper describes the safety features that are important to a robotic workstation. It also discusses the safety costs involved and gives some examples. Some of the important legal aspects are further highlighted.

Cornelius J. Fourie en Freda Potgieter

Departement Bedryfsingenieurswese

Universitieit van Stellenbosch

Suid-Afrika 


\section{Algemeen}

Daar word baie min geskryf oor die beveiliging van robotstelsels en dit blyk 'n onderwerp te wees wat beide robotgebruikers en robotvervaardigers huiwer om in detail te bespreek. Tog word die grootste meerderheid van robot veiligheidsprobleme in die praktyk opgelos deur logiese tegnieke wat beide 'n veilige en produktiewe omgewing tot gevolg het. Wanneer daar 'n outomatiese toestel of 'n robot ontwerp en ontwikkel word, moet daar ALTYD vir die menslike element voorsiening gemaak word. Die rede hiervoor is dat ' $n$ wye verskeidenheid mense met die robot of toestel in kontak sal kom. Dit sluit in die operateur, programmeerder, onderhoud- en skoonmaak personeel, ander ingenieurs en die toevallige besoeker. Dit is die verantwoordelikheid van die ontwerpingenieur om hierdie gebruikers te beveilig - dus moet beide die menslike en die kapitale elemente in die stelsel ten alle tye beskerm word.

\section{2. 'n Oorsig van die robotstelsel}

Vir die doeleindes van toetsing, onderhoud en veiligheid, kan die robotstelsel beskou word as bestaande uit ' $n$ aantal boublokke, naamlik:

- Die meganiese stelsel - bestaande uit hefbome, balke, draaispille en laers en is die mees sigbare komponent uit 'n buitestaander se oogpunt.

- Die motiewe stelsel - bestaande uit motore en aktueerders wat die bruto krag van die primêre kragbron omsit na die beweging van die meganiese stelsel.

- Die beheerstelsel - hierdie komponent tree baie soos die mens se sintuie op en verskaf dan terugvoer aan die rekenaarstelsel oor waar die robot is en wat hy doen.

- Die rekenaarstelsel - hierdie is die prosesseringselement van die totale stelsel. Die aktiwiteite van die robotstelsel moet gekoördineer word om te verseker dat die stelsel as 'n geheel op die verwagte manier optree.

- Die sagteware stelsel - hierdie komponent koördineer die aktiwiteite van die rekenaarstelsel op baie dieselfde wyse as wat die menslike brein dit doen.

- Die koppelvlakstelsel - hierdie is die kommunikasienetwerk wat die rekenaar met die buitewêreld laat kommunikeer en vice versa.

Gesamentlik is hierdie boublokke die robotstelsel met 'n vasgestelde beheer hierargie, maar elkeen kan ook afsonderlik funksioneer. Die meganiese stelsel word deur die motiewe stelsel beheer en aangedryf. Die motiewe stelsel skakel hidrouliese, elektriese of pneumatiese energie (of enige kombinasie hiervan) om in bewegings en dus gevolglik in arbeid. Die rekenaarstelsel verskaf die instruksies aan die beheerstelsel wat dit aan die motiewe stelsel moet deurgee. Die program vir die rekenaarstelsel word via koppelvlak kanale verskaf.

In 'n ideale stelsel sal al die komponente gebalanseerd saamwerk en die beheer hierargie glad verloop. Omdat al hierdie boublokke egter onderling afhanklik is, sal 'n defek in een die hele stelsel onvoorspelbaar laat optree. Hierdie onvoorspelbaarheid is die oorsaak van onveilige situasies.

\section{Sone/vlakke konsep van beveiliging}

Hierdie wyse van toedeling van die robot se werksarea is deur die Amerikaanse Buro van Standaarde daargestel. Die sones word in Figuur 1 aangedui. 


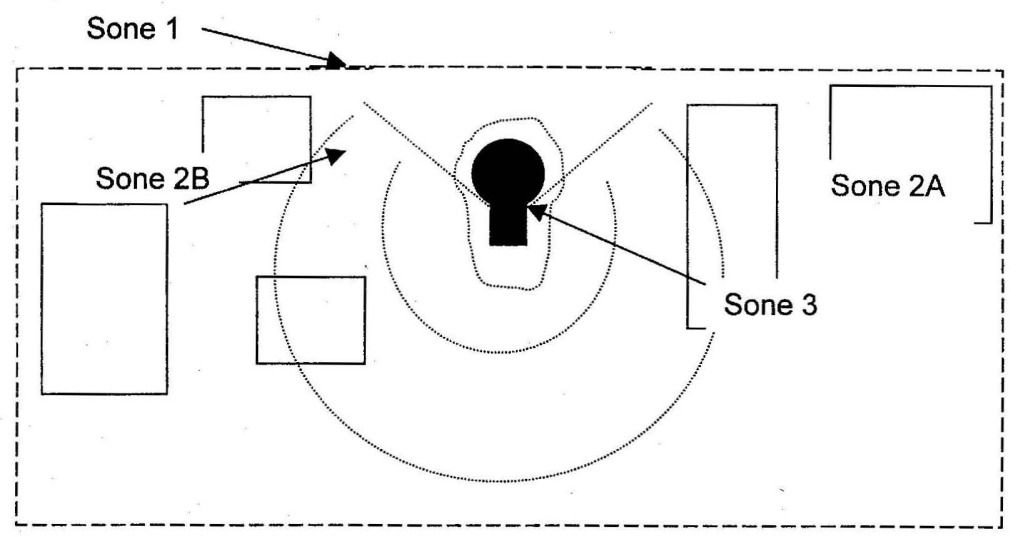

Figuur 1: Toedeling van robot se werkareas in sones

In hierdie figuur is dit duidelik dat sone 1 die waarneming van binnedringing van die omtrek is. Dit is gewoonlik 'n fisiese struktuur wat vurkhysers en ander trokke kan uithou, maar nie noodwendig mense kan buite hou nie. Sone $2 \mathrm{~A}$ is binne die skerm van die omtrek van die robot se werksarea, maar buite die bereik van die robot se arm. Sone 2B is egter binne die robot se sogenaamde werksgebied ("work envelope") terwyl sone 3 'n area rondom die robot self is wat saam met sy arm beweeg. Die beveiliging van elke sone word afsonderlik bespreek.

\subsection{Vlak 1 beveiliging}

Vlak 1 word beveilig deur 'n beskermingsreëling. Ander tegnieke wat gebruik kan word om mense ook buite te hou, is hoër omheinings van die skakelketting tipe of plexiglas. Die voordeel hiervan is dat dit moeilik is om te omseil en dat verbygangers ook beskerm word teen voorwerpe wat uitgewerp word uit die werksel. Daar is verskeie maniere om toegang tot vlak 1 te verkry vir onderhoud of beweging van die robotapparaat. Daar word gegrendelde deure ingesit sodat die krag outomaties afsluit indien dit oopgemaak word en robotbeweging gestaak word. Daar kan van liggordyne gebruik gemaak word waar omheinings nie toepaslik is nie - hier sal die grendels die robot beweging onderbreek en twee afsonderlike aksies van die operateur vereis om voort te gaan met die siklus. Dwarsdeur die sel en alle sones kan daar ook van noodstoppe gebruik gemaak word - ook op die beheerpaneel en sogenaamde beheerkassie ("teach pendant"). 'n Baie eenvoudige manier om die produksie area te beveilig is ' $n$ vaste omtrek hindernis of heining. Toegangshekke is wel nodig vir onderhoud doeleindes, maar hierdie word met limietskakelaars toegerus wat onmiddelik die werking van die robot onderbreek as die hek gedurende operasie oopgemaak word.

Selfs die oorhoofse area moet beveilig word om robot botsings te voorkom. As die robot se bereik die dakbalke of ander strukture in die dak van 'n gebou kan bereik, is 'n mate van beheer nodig om skade aan die robot, gebou of beide te voorkom. Een opsie is om foto-elektriese sensors aan te bring wat 'n sein aan die beheerder sal voorsien indien die robotarm te hoog lig. 'n Ander opsie kan wees om die robot in 'n put te verlaag, maar daar is probleme hiermee omdat die $x-y$ area in die put kleiner is as die robot se werksarea en die robot dus met die vloer kan bots. Programmering moet dus met groot sorg uitgevoer word of die $x-y$ area van die put moet fisies groter gemaak word. 


\subsection{Vlak 2 beveiliging}

Liggordyne wat van wit lig of infrarooi lig gebruik maak, is hier redelik populêr. Die primêre probleme wat hiermee gepaard gaan, is die onderhoud, opstelling en skoonmaak van die optika. Soms sal 'n werker en die robot 'n werkstasie moet deel. Dit kan byvoorbeeld gebeur wanneer die werker komponente vir die robot moet aangee vir optel. In so 'n geval moet dieselfde fisiese area gedeel word. 'n Sogenaamde glyvoerbaan kan egter ingespan word om komponente na die robot vanaf die afsonderlike werkstasie van die operateur buite die robot se werksarea te vervoer en terselfdertyd voltooide komponente weer terug te vervoer na die werker.

'n Nuttige beveiligingsmeganisme is die druk-sensitiewe matte waarop getrap kan word om krag te onderbreek. Hier kan van elektriese, pneumatiese of optiese waarneming gebruik gemaak word.

'n Belangrike vereiste waaraan voldoen moet word, is dat daar nog steeds druk volgehou moet word al word die krag onderbreek (byvoorbeeld in hidrouliese toepassings) sodat die robotarm nie na die vloer toe val en iemand of iets in die proses beseer nie. Ernstige skade kan so aan die endeffektor aangerig word. Wanneer die krag onderbreek word, sal die programgeheue verlore gaan indien die robot nie deur batterykrag ondersteun word nie. Wanneer die robot dan weer begin word, sal dit moontlik vanself na die oorspronklike beginposisie wil terugkeer en so 'n gevaar vir personeel inhou. Die meeste vervaardigers van robotte maak voorsiening vir batterykrag.

Beligting in die area van robotbeweging is baie belangrik, al hoef die robot self nie in verligte areas te werk nie. Die werkers moet duidelik kan sien indien doeltreffende onderhoud gedoen word asook alle instruksies kan lees om die beheerpaneel korrek te bedryf.

\subsection{Vlak 3 beveiliging}

Daar is twee manier waarop die werker in hierdie area beveilig kan word, naamlik die gebruik van druk-sensitiewe velle op die robot arm en werkers wat self druk-sensitiewe frokkies dra wat met die robotbeheer skakel.

\section{Die robot en die werksproses}

Die vervanging van mense met robotte beteken nie dat daar minder aandag aan menslike gesondheid en veiligheid gegee gaan word nie. Aangesien personeel steeds die werksarea moet binnegaan om die toerusting te onderhou en diens, en om die robot te bereik as 'n nuwe komponent gebruik gaan word, moet bykomende veiligheidsmaatreëls voorsien word. Die robot moet byvoorbeeld nie in staat wees om vonke te genereer van óf die meganisme self óf die meganisme in wisselwerking met die omgewing nie. Voorsorg moet getref word om die opbou van statiese elektrisiteit te voorkom deur alle toestelle te aard. Sensoriese toestelle moet met lae spannings werk en lae strome moet gebruik word waar moontlik om die moontikheid van risiko tydens onklaarraking te minimeer.

Soms mag dit selfs nodig wees om van robotte gebruik te maak wat van hidrouliese in plaas van elektriese krag gebruik maak. Die beheerpaneel moet vêr van die robot self geplaas word om die risiko van vonke of sekere vorms van elektriese ontbranding of vlambare gasse te vermy. 


\section{Moontlike falings van die robotstelsel}

Alhoewel die oorsake van falings van die stelsel baie uiteenlopend is, word hulle slegs op 'n paar maniere openbaar. Die enkele mees beduidende teken van 'n potensiële faling is wisselvallige gedrag of onverwagse bewegings. Dit kan klein of groot afwykings van die vooropgestelde pad van beweging insluit. Klein afwykings is aanduidend van 'n stelsel wat nie meer ingestel is nie en kan opgelos word deur die oplyning van die beheerstelsel aan te pas en die meganiese integriteit van die stelsel na te gaan. Gereelde onderhoud is dus nodig om te verseker dat hierdie tipe probleem nie van 'n meer ernstige aard raak nie. Groot afwykings is aanduidend van een of ander fundamentele probleem, waarvan 'n paar simptome en moontlike oorsake in Tabel 1 gegee word :

Tabel 1: Simptome en oorsake van groot afwykings

\begin{tabular}{|c|c|}
\hline Simptome & Moontlike oorsake \\
\hline $\begin{array}{c}\text { Groot onwillekeurige rukkings } \\
\text { (sporadies) }\end{array}$ & $\begin{array}{c}\text { Sagteware korrupsie } \\
\text { Los meganiese koppelings } \\
\text { Verslete motoronderdele } \\
\text { Motor afwykings } \\
\text { Los posisie sensors } \\
\text { Elektroniese komponente } \\
\text { Los of gebreekte verbindings }\end{array}$ \\
\hline Groot afwykings van geleerde pad & $\begin{array}{c}\text { Beheerstroombaan defektief } \\
\text { Sagteware korrupsie tydens leer } \\
\text { Los koppelings of draers }\end{array}$ \\
\hline Vries tydens werksiklus & Kragonderbreking \\
& Beheerstroombaan defektief \\
& Proses faling \\
& Rekenaar defektief \\
\hline $\begin{array}{c}\text { Robot beweeg teen maksimum spoed tot } \\
\text { die limiet van beweging en vries dan }\end{array}$ & $\begin{array}{c}\text { Meganiese defek } \\
\text { Motor faling } \\
\end{array}$ \\
& $\begin{array}{c}\text { Beheerstelsel faling } \\
\text { Rekenaar faling }\end{array}$ \\
\hline
\end{tabular}

Dit is nodig dat 'n soorgelyke kaart (wat sal verskil van robot tot robot) gebruik word deur technici en ingenieurs vir falingsanalises. Hierdie is egter ongewone gebeurtenisse wat behoorlik in perspektief gesien moet word. Die meeste robotstelsels het 'n werkslewe van tussen 5 en 15 jaar as dit korrek onderhou word. 'n Groot afwyking soos in die tabel bespreek, sal tipies slegs een of twee keer in die robotstelsel se totale leeftyd voorkom. Tog moet hierdie skaars voorkomste voorspel word en daarvoor voorsiening gemaak word

\section{Ontwerpsprosedure vir robot veiligheid}

Die volgende eenvoudige stappe moet gevolg word in die ontwerp vir veiligheid :

1. Begin met ' $n$ eenvoudige stelsel.

2. Gesels met die personeel op die fabrieksvloer - hulle het die nodige ondervinding en bied 'n onuitputbare bron van relevante inligting.

3. Baie tyd moet aan opleiding van die betrokkenes spandeer word, asook aan die ontfouting van http://sajie.journals.ac.za 
die stelsel (hier kan die ontwerpers en verkopers van die robot en/of sagteware van groot waarde wees).

4. Hou ten alle tye die menslike element in gedagte en ontwerp daarvoor.

Wat die uitleg van die fabrieksvloer self aan betref, moet die materiaalhantering toerusting en ander moontlike struikelblokke in gedagte gehou word. Dit is baie belangrik dat die sogenaamde vaspen areas ("pinch points") geidentifiseer word. Verskeie gevalle van noodlottige beserings is veroorsaak deurdat werkers vasgepen word teen vaste voorwerpe in 'n werksel. Dit is gevolglik baie belangrik dat daar voldoende speling in die ruimte rondom die robot is (benodig meer spasie as die mens).

\section{Skakelaars}

Die beveiliging van robotte en ander geoutomatiseerde sisteme vereis dat die meeste operateurbeheer skakelaars slegs een stabiele toestand het, naamlik af. Daar moet gevolglik dus 'n positiewe operateur aksie volgehou word om die skakelaar aan te hou. Die voordeel van enkel-stabieletoestand skakelaars is dat beheer waar en wanneer nodig uitgeoefen kan word om die operasionele toestand van die stelsel te verander.

Foto-elektriese sensors kan op verskeie punte rondom die robot se werksarea geplaas word om as veiligheidsmeganisme op te tree om die robot se beweging te stop indien iemand onwettiglik die werksruimte binnegaan. ' $n$ Leier in robotvervaardiging, Prab, het 'n beleid dat daar saam met elke nuwe robot 'n skakelketting hindernis ingesluit word om die wersarea te omring. Die hindernis word met elektronies gegrendelde hekke toegerus: as die hekke oopgemaak word, sal die robotbeweging onmiddelik stop. Infrarooi hindernis toestelle kan ook gebruik word om personeel uit die werksarea te hou gedurende robot werking. Hulle word ineengesluit met die robot se beheerstelsel en enige ongewensde toegang sal dan die robotbeweging onmiddelik staak.

\section{Programmering en toetsing}

'n Goeie manier om robotte se omgewing te beveilig is om die spoed van beweging dienooreenkomstig aan te pas. So het 'n programmeertaal soos VAL bv. 'n SPEED-opdrag (afkorting SP) met 'n heeltal na die opdrag wat die \% van die standaardspoed (tussen 0 en 327\%) aandui. Hierdie is nuttig om die robot en die program self te vertraag terwyl toetsing plaasvind. Daar bestaan ook 'n ABORT opdrag (of net A) wat die program op enige punt gedurende uitvoering kan stop. Daar bestaan ook gewoonlik 'n sogenaamde noodstop drukknoppie vir die arm se kragbron wat vir noodgebruik geskik is.

Gedurende die programmering van 'n robot is die beste beskerming teen beserings die goeie opleiding van die tegnici en die beskikbaarheid van noodstoppe. Een reël wat dikwels toegepas word, is dat niemand in die werksarea mag beweeg terwyl die robotarm se krag aangeskakel is nie. Alhoewel dit 'n goeie reël is, is dit nie altyd prakties tydens die programmering of opstelfases nie.

Tydens eksperimentering (waneer die presiese werksarea van die robot nog bepaal moet word) moet die werksgebied ontruim wees. 


\section{Implementering}

Tydens hierdie fase is dokumentasie baie belangrik. Tekeninge van die elektroniese en meganiese stelsels moet gemaak en op 'n maklik toeganklike plek gestoor word. 'n Duidelike en volledige beskrywing van die robot se werksiklus moet ook ingesluit word. 'n Voorlopige veiligheidsanalise asook dokumentasie van enige veranderinge en die moontlike impak wat die voorgestelde verandering op die veiligheidsanalise kan hê, moet ingesluit word.

Opleiding is noodsaaklik vir die personeel wat betrokke is op alle vlakke (dit sluit ingenieurs asook die skoonmaak- en onderhoud personeel in). Hierdie spesifieke opleiding moet gedoen word met die individu se kennis en ondervinding van robotaksies in gedagte.

Robot opleiding wat in 'n maatskappy moet plaasvind, kan in vyf kategorieë verdeel word, naamlik:

- Bewusmaking

- Regverdiging

- Toepassing

- Werksverrigting en onderhoud en

- Veiligheid self.

'n Toepaslike voorkomende instandhoudingsprogram is nodig om die frekwensie van noodprobleme te verminder. Die doelwit van voorkomende instandhouding is om die toerusting teen periodieke intervalle te diens om die voorvalle van falings te verminder. Deur gereelde diens kan die aantal falings verminder word en die intensiteit van dié wat wel voorkom, kan afneem. Dit behels die toetsing, skoonmaak en moontlike vervanging van meganiese en elektriese komponente soos seëls, draers, kleppe en ander onderdele wat verweer.

\section{Die koste verbonde aan veiligheid}

Daar kan geredeneer word dat die koste van beveiliging van 'n outomatiese stelsel ingesluit moet word by die koste van toerusting. Dit is egter so 'n belangrike afdeling dat dit afsonderlik bereken behoort te word. Die spesifieke veiligheidsvereistes moet vir elke toepassing afsonderlik bereken word. Die belangrikste elemente van die veiligheidstelsel is :

- Veiligheidsomheinings - hierdie kan draadskerms, soliede skerms of 'n kombinasie van beide wees. Dit word individueel ontwerp vir elke toepassing maar kan ook uit 'n paar standaard eenhede saamgevoeg word.

- Alarmtoestelle - hierdie is tipies noodstoppe wat die wanfunksionering van operateurs of toerusting aandui.

- Operateur beskermingstoestelle - hierdie word gebruik om te verseker dat die operateur uit die pad van die toerusting is tydens werking. Drukmatte, liggordyne, skerms en tralies is voorbeelde hiervan.

- Veiligheidsopleiding - hierdie tipe opleiding moet aan elkeen gegee word wat met robotstelsels werk of selfs net in kontak kom daarmee. Dit beteken soms tyd wat weg van die werksarea self spandeer word.

Die bogenoemde elemente saam vorm die veiligheidstelsel, wat tipies ongeveer $10 \%$ van die koste van die basiese stelsel uitmaak. Die koste van die ontwikkeling en dokumentasie van veilige werkswyses, wat gevolglik administratiewe en prosedurale bystand insluit, maak ook deel hiervan uit. 


\section{Wetlike aspekte}

Die gemeenskap is glad nie baie vergewinsgesind wanneer daar iets met outomatiese toerusting verkeerd gaan en iemand beseer word nie. Dit is bestuur se verantwoordelikheid om aan die voorgestelde maatreëls vir veiligheid (in Suid-Afrika byvoorbeeld weergegee in die gereeldopgedateerde Health and Safety Regulations) te voldoen en sy werkers so vêr moontlik van ongelukke te beskerm. Die formele wetgewing wat hierdie verantwoordelikheid aanspreek, beskryf gewoonlik in groot detail die voorsorgmaatreëls vir die werksomgewing en ook meer spesifiek vir die voorgestelde masjien en proses. Die Wet op Beroepsgesondheid en Veiligheid (Wet 85 van 1993) handel oor algemene punte soos huishouding en netheid van die fabrieksvloer, werksomstandighede, en ander aspekte van die werknemer se welvaart. Die onus rus op die werkgewer om 'n geskrewe beleid in verband met gesondheid en veiligheid by die werk op te stel en gereeld te hersien. Ongelukkig is dit moeilik om die veiligheidsmaatreëls op datum te hou met die nuwe tegnologieë waarby robotte betrokke is. Die ontwikkelaar en toepasser van hierdie nuwe tegnologie moet dus deur logika en algemene veiligheidsbeginsels gelei word en dus moet voorsorgmaatreëls wat ontwikkel word, redelik prakties van aard wees en ooreenstem met huidige metodieke in soortgelyke prosesse. Dit is nodig om die vermoë om moontlike falings te voorspel, te ontwikkel en hiervoor is ' $n$ kennis van die tegnologie wat gebruik word, nodig.

'n Groot deel van die verantwoordelikheid vir beveiliging lê egter by die werker self en in hierdie opsig is opleiding betreffende die korrekte en verantwoordelike gebruik van outomatiese toerusting ' $n$ vereiste. Die wette wat die veiligheid van vervaardigingtoerusting betref, vereis baie duidelik dat die toerusting falingsbestand moet wees. Dit is veral belangrik in die leerfase van die gebruik van robotte omdat man en masjien dan in nabye omgewings saamwerk. Enige noodgeval moet die robot in so 'n toestand laat dat dit geen gevaar inhou vir iemand wat naby staan nie. Dit moet ook ten alle tye moontlik wees om met veiligheidsgrendels te koppel (sensor toestelle of noodstoppe) wat die totale stelsel in ' $n$ veilige toestand kan laat ten tye van enige onverwagse gebeurtenisse. Dit is natuurlik net betekenisvol as die veiligheidsvereistes deur almal verstaan word en voldoende is vir die toepassing.

Die idee van 'n industriële robot wat iemand beseer of doodmaak, is afskuwelik vir die gemeenskap, maak nie saak hoe ongereeld dit gebeur nie. In een geval in Amerika was die regter se uitspraak:

\footnotetext{
"Who serves whom? I think we have to be very careful that we don't go backwards to the kinds of notions we had during the industrial revolution that people are expendable."
} 


\section{Bibliografie}

Asfahl, CR, 1992, "Robots and Manufacturing Automation." Tweede Uitgawe, John Wiley \& Sons, Inc.

Groover et al., 1986, "Industrial Robotics: Technology, Programming and Applications." McGrawHill Inc.

IEEE Home Video Tutorial: "Industrial Robotics for the Electrical Engineer." Talk given by Prof. Rod Simmons, University of Cincinnati.

Leatham-Jones, B, 1987, "Elements of Industrial Robotics." Pitman Publishing London.

Morgan, C, 1984, "Robots Planning and Implementation.” IFS (Publications) Ltd.; UK. 